\title{
ANALISIS PERILAKU KONSUMEN TERHADAP PERMINTAAN BUAH NAGA(Hylocereus Polyrhizus) (Studi Pada Pasar Mimbaan Kecamatan Panji)
}

\section{A CONSUMER BEHAVIOR ANALYSIS OF REQUESTS FOR DRAGON FRUIT(Hylocereus Polyrhizus) (A Study at Mimbaan Market, Panji District)}

\author{
Afri Prayudi ${ }^{1)}$ Yohanes Nangameka ${ }^{2)}$ Puryantoro ${ }^{3)}$ \\ Afriprayudi0gmail.com \\ ${ }^{1,2,3}$ Fakultas Pertanian, Universitas Abdurachman Saleh
}

\begin{abstract}
ABSTRAK
Penelitian ini bertujuan untuk mengetahui perilaku konsumen dari beberapa faktor seperti pendapatan, harga barang, selera individu, status sosial dan kebudayaan yang berpengaruh terhadap permintaan buah naga di Pasar Mimbaan Situbondo dan mengetahui secara simultan pendapatan, harga barang, selera individu, status sosial dan kebudayaan berpengaruh terhadap permintaan buah naga di Pasar Mimbaan Situbondo. Penelitian ini dilakukan di Pasar Mimbaan Kecamatan Panji Kabupaten Situbondo pada Bulan Mei hingga Bulan Juni. Metode yang digunakan dalam penelitian ini yaitu studi kasus. Pengumpulan data dilakukan dengan metode accidental sampling. Analisis yang digunakan dalam penelitian ini yaitu deskriptif. Teknik yang digunakan untuk menganalisis faktor-faktor dari perilaku konsumen terhadap permintaan yaitu menggunakan Analisis Regresi Linier Berganda, Uji Parsial (Uji t) dan Uji Simultan (Uji F). Untuk mengalisis perilaku konsumen dari beberapa faktor seperti pendapatan, harga barang, selera individu, status sosial dan kebudayaan yang berpengaruh terhadap permintaan buah naga dan mengetahui secara simultan pendapatan, harga barang, selera individu, status sosial dan kebudayaan berpengaruh terhadap permintaan buah naga di Pasar Mimbaan Situbondo. Dengan hasil penelitian menunjukkan Perilaku konsumen dari beberapa faktor seperti pendapatan, harga barang, selera individu, status sosial dan kebudayaan, hanya harga barang dan status sosial yang mempengaruhi permintaan buah naga di Pasar Mimbaan, sedangkan ketiga faktor seperti pendapatan, selera individu, dan kebudayaan tidak berpengaruh terhadap permintaan buah naga dan secara bersamasama pendapatan, harga barang, selera individu, status sosial dan kebudayaan berpengaruh terhadap permintaan buah naga di Pasar Mimbaan.
\end{abstract}

Kata Kunci : Perilaku Konsumen, Faktor Konsumen, Buah Naga. 


\title{
Volume 3 , Nomor 1, Juli
}

\begin{abstract}
This study aims to determine consumer behavior from several factors such as income, price of goods, individual tastes, social status and culture that affect the demand for dragon fruit in the Mimbaan Situbondo Market and know simultaneously income, price of goods, individual tastes, social status and culture influence on the demand for dragon fruit in Situbondo Mimbaan Market. This research was conducted at Mimbaan Market, Panji Subdistrict, Situbondo Regency from May to June. The method used in this research was a case study. Data collection is done by accidental sampling method. The analysis used in this research is descriptive. Techniques used to analyze the factors of consumer behavior towards demand are using Multiple Linear Regression Analysis, Partial Test (t Test) and Simultaneous Test (F Test). To analyze consumer behavior from several factors such as income, price of goods, individual tastes, social status and culture that affect the demand for dragon fruit and know simultaneously income, price of goods, individual tastes, social status and culture affect the demand for dragon fruit in Mimbaan Situbondo Market . With the results of the study show consumer behavior from several factors such as income, price of goods, individual tastes, social status and culture, only the price of goods and social status affect the demand for dragon fruit in Mimbaan Market, while the three factors such as income, individual tastes, and culture have no effect on the demand for dragon fruit and together income, price of goods, individual tastes, social status and culture influence the demand for dragon fruit in Mimbaan Market.
\end{abstract}

\section{Keywords : Consumers Behavior, Consumers Behavior Factors, Dragon Fruit.}

\section{PENDAHULUAN}

Buah naga (Hylocereus sp.) tumbuhan yang berasal dari daerah beriklim tropis kering. Pertumbuhan buah naga dapat dipengaruhi oleh suhu, kelembaban udara, keadaan tanah dan curah hujan. Habitat asli buah naga berasal dari negara Meksiko, Amerika Utara dan Amerika Selatan bagian utara. Namun buah naga hingga saat ini telah dibudidayakan di Indonesia seperti di Jember, Malang, Pasuruan dan daerah lainnya. Di Indonesia, buah naga mulai populer sejak tahun 2000, dimana dalam satu tanaman biasanya menghasilkan $1 \mathrm{~kg}$ buah. Dalam satu hektar tanaman buah naga akan menghasilkan sekitar 6-7 ton buah naga sekali musim panen bahkan dapat mencapai lebih dari 50 ton per tahun jika usaha budidaya buah naga berhasil (Kristanto, 2008). 


\section{Volume 3 , Nomor 1, Juli}

2019 CERMIN : JURNAL PENELITIAN

Buah naga adalah salah satu buah yang masih menjadi primadona bagi masyarakat Jawa Timur, seperti Jember, Banyuwangi, Lumajang dan termasuk Situbondo. Situbondo adalah salah satu Kabupaten yang konsumsi buah naga yang cukup tinggi. Buah naga khususnya di pasar mimbaan, Kecamatan Panji, Kabupaten Situbondo menjadi salah satu tempat penjualan buah naga terbesar di Situbondo. Saat ini permintaan buah naga di Situbondo mengalami kenaikan, karena adanya perubahan harga yang terjadi akibat melimpahnya buah naga di daerah-daerah penghasil buah naga yang mengalami panen raya.

Permintaan adalah banyaknya jumlah barang yang diminta pada suatu pasar tertentu dengan tingkat harga tertentu pada tingkat pendapatan tertentu dan dalam periode tertentu. Secara periode permintaan dari seorang individu atau masyarakat terhadap suatu barang ditentukan oleh antara lain harga barang yang dimaksud, tingkat pendapatan, jumlah penduduk, harga barang lain atau substitusi, dan lainlain (Sarnowo dan Sunyoto, 2013). Dimana hukum permintaan berbunyi "Jika harga suatu barang meningkat, maka jumlah barang yang diminta akan turun. Sebaliknya, jika harga suatu barang turun, maka jumlah barang yang akan diminta akan meningkat (Cateris Paribus)". Karena harga buah naga saat ini di tingkatan pedagang hanya dihargai Rp 2.500 hingga Rp 3.500 per kilogram $(\mathrm{kg})$. Biasanya harga normal buah naga di tingkat pedagang berkisar Rp 10.000 hingga Rp 15.000/kg. Hal itulah yang memperngaruhi prilaku konsumen terhadap permintaan buah naga di Situbondo bertambah (Data Tahun 2019).

Mowen (1990 : 5) mengatakan bahwa perilaku konsumen adalah studi unit-unit dan proses pembuatan keputusan yang terlibat dalam menerima, menggunakan dan penentuan barang, jasa, dan ide. Definisi tersebut menggunakan istilah unit-unit pembuat keputusan, karena keputusan bisa dibuat oleh individu atau kelompok. Definisi tersebut juga mengatakan bahwa konsumsi adalah proses yang diawali dengan penerimaan, konsumsi, dan diakhiri dengan penentuan (disposition). Tahap penerimaan menganalisa faktor-faktor yang mempengaruhi pilihan konsumen 


\section{Volume 3 , Nomor 1, Juli}

2019 CERMIN : JURNAL PENELITIAN

terhadap produk, tahap konsumsi menganalisa bagaimana konsumen senyatanya menggunakan produk yang diperoleh.

Berdasarkan penjelasan yang telah dipaparkan diatas, maka dapat diidentifikasikan rumusan masalah sebagai berikut : 1. Apakah perilaku konsumen dari beberapa faktor seperti pendapatan, harga barang, selera individu, status sosial dan kebudayaan berpengaruh terhadap permintaan? 2. Apakah secara simultan pendapatan, harga barang, selera individu, status sosial dan kebudayaan berpengaruh terhadap permintaan?

\section{METODE PENELITIAN}

\section{Populasi dan Sampel}

Pengertian populasi menurut Sugiyono (2008) adalah wilayah generelisasi yang terdiri atas obyek/subyek yang mempunyai kualitas dan karakteristik tertentu yang ditetapkan oleh peneliti untuk dipelajari dan kemudian ditarik kesimpulannya. Maka populasi yang diambil dalam penelitian ini adalah konsumen yang tidak diketahui jumlahnya di Pasar Mimbaan Kecamatan Situbondo Kabupaten Situbondo.

Sedangkan pengertian sampel menurut Sugiyono (2008) adalah bagian dari jumlah dan karakteristik yang dimiliki oleh populasi tersebut. Dalam penelitian ini dijadikan sampel berjumlah 50 orang. Dan menggunakan jenis Sampling aksidental, yaitu teknik penentuan sampel berdasarkan kebetulan, yaitu siapa saja yang secara kebetulan bertemu dengan peneliti dapat digunakan sebagai sampel, bila dipandang orang yang kebetulan ditemui itu cocok sebagai sumber data (Sugiyono, 2001: 60).

\section{Analisis Regresi Linear Berganda}

Analisis ini digunakan untuk mengetahui seberapa besar pengaruh variabel bebas yaitu pendapatan $\left(\mathrm{X}_{1}\right)$, harga barang $\left(\mathrm{X}_{2}\right)$, selera individu $\left(\mathrm{X}_{3}\right)$, status sosial $\left(\mathrm{X}_{4}\right)$, dan kebudayaan $\left(\mathrm{X}_{5}\right)$ terhadap variabel terikat yaitu permintaan $(\mathrm{Y})$ di Pasar Mimbaan Kecamatan Panji Kabupaten Situbondo. Menurut Sugiyono, (2010:59) untuk mengetahui pengaruh variabel bebas terhadap variabel terikat digunakan rumus 


\section{Volume 3 , Nomor 1, Juli}

analisis regresi linier berganda sebagai berikut:

$$
Y=a+b_{1} x_{1}+b_{2} x_{2}+b_{3} x_{3}+b_{4} x_{4}+b_{5} x_{5}+e
$$

Keterangan:

Y : Permintaan

$\mathrm{X}_{1}$ : Pendapatan

$\mathrm{X}_{2}$ : Harga Barang

$\mathrm{X}_{3}$ : Selera Individu

$\mathrm{X}_{4}$ : Status Sosial

$\mathrm{X}_{5}$ : Kebudayaan

$\alpha:$ Konstanta

$b 1-b 2$ : Koefisien regresi

$e:$ Toleransi ketidakaktifan/epsilon

\section{Pengujian Secara Parsial (Uji t)}

Uji t (t-test) melakukan pengujian terhadap koefisien regresi secara parsial, pengujian ini dilakukan untuk mengetahui signifikansi peran secara parsial antara variabel independen terhadap variabel dependen dengan mengasumsikan bahwa variabel independen lain dianggap konstan. Dasar pengambilan keputusan (Ghozali, 2005:110):

a. Dengan membandingkan nilai $t_{\text {hitungnya }}$ dengan $t_{\text {tabel }}$, dengan tingkat signifikansi $95 \%$ atau $\alpha 5 \%$.

1) Apabila $t_{\text {hitung }} \geq t_{\text {tabel }}$ atau $-t_{\text {hitung }} \leq-t_{\text {tabel }}$, maka Ho ditolak dan Ha diterima, artinya variabel bebas secara parsial berpengaruh signifikan terhadap variabel terikat.

2) Apabila $t_{\text {hitung }}<t_{\text {tabel }}$ atau $-t_{\text {hitung }}>-t_{\text {tabel }}$, maka Ho di terima dan Ha di tolak, artinya variabel bebas secara parsial tidak berpengaruh signifikan terhadap variabel terikat. 


\section{Volume 3 , Nomor 1, Juli}

b. Dengan menggunakan angka probabilitas signifikansi.

1) Apabila angka probabilitas signifikansi $>0,05$, maka Ho diterima dan Ha ditolak, artinya variabel bebas secara parsial tidak berpengaruh signifikan terhadap variabel terikat.

2) Apabila angka probabilitas signifikansi < 0,05, maka Ho ditolak dan $\mathrm{Ha}$ diterima, artinya variabel bebas secara parsial berpengaruh signifikan terhadap variabel terikat.

Penentuan nilai $\mathrm{t}$ tabel berdasarkan taraf signifikansi sebesar 95\% dan taraf derajat kebebasan $(\mathrm{df})=\mathrm{n}-\mathrm{k}(\alpha / 2)$.

Dimana:

$$
\begin{array}{ll}
\mathrm{df} & =\text { degree of freedom } \mathrm{n}=\text { jumlah sampel } \\
\mathrm{k} & =\text { jumlah variabel (bebas dan terikat) } \\
\alpha & =5 \%
\end{array}
$$

\section{Pengujian Secara Simultan (Uji F)}

Uji F adalah pengujian terhadap koefisien regresi secara simultan. Pengujian ini dilakukan untuk mengetahui pengaruh semua variabel independen yang terdapat di dalam model secara bersama-sama (simultan) terhadap variabel dependen.Uji $F$ dalam penelitian ini digunakan untuk menguji signifikasi pengaruh pendapatan, harga barang, selera individu, status sosial, dan kebudayaan terhadap permintaan secara simultan dan parsial. Dasar pengambilan keputusan (Ghozali, 2005):

a. Dengan membandingkan nilai $F_{\text {hitung }}$ dengan $F_{\text {tabel }}$

1) Apabila $F_{\text {hitung }} \geq F_{\text {tabel}}$, maka Ho ditolak dan Ha diterima, artinya variabel bebas secara simultan berpengaruh signifikan terhadap variabel terikat.

2) Apabila $F_{\text {hitung }}<F_{\text {tabel }}$, maka Ho di terima dan Ha ditolak, artinya variabel bebas secara simultan tidak berpengaruh signifikan terhadap variabel terikat.

b. Dengan menggunakan angka probabilitas signifikansi 


\section{Volume 3 , Nomor 1, Juli}

1) Apabila probabilitas signifikansi > 0,05, maka Ho diterima dan Ha ditolak, artinya variabel bebas secara simultan tidak berpengaruh signifikan terhadap variabel terikat.

2) Apabila probabilitas signifikansi $<0,05$, maka Ho ditolak dan Ha diterima, artinya variabel bebas secara simultan berpengaruh signifikan terhadap variabel terikat.

Penentuan nilai $\mathrm{F}$ tabel diperoleh dari:

$$
\begin{aligned}
& \mathrm{dfN} 1=\mathrm{k}-1 \\
& \mathrm{dfN} 2=\mathrm{n}-\mathrm{k}
\end{aligned}
$$

Dimana:

$$
\begin{array}{ll}
\mathrm{df} & =\text { degree offreedom } \\
\mathrm{n} & =\text { jumlah sampel } \\
\mathrm{k} & =\text { jumlah variabel (bebas dan terikat) }
\end{array}
$$

\section{HASIL DAN PEMBAHASAN}

\section{Analisis Regresi Berganda}

Untuk mengetahui model atau bentuk hubungan pengaruh antar variabel dan unutk mengetahui positif atau negatifnya pengaruh variabel bebas (X) yaitu pendapatan (X1), harga barang (X2), selera individu (X3), status sosial (X4), dan kebudayaan (X5) terhadap variabel terikat (Y) Permintaan dimana dari sampel yang diperoleh, digunakan analisis regresi linier berganda dengan menggunakan rumus sebagai berikut : 
Tabel 1. Regresi Linier Berganda

Coefficients $^{\mathbf{a}}$

\begin{tabular}{|c|c|c|c|c|c|}
\hline \multirow[b]{2}{*}{ Model } & \multicolumn{2}{|c|}{$\begin{array}{l}\text { Unstandardized } \\
\text { Coefficients }\end{array}$} & \multirow{2}{*}{$\begin{array}{c}\begin{array}{c}\text { Standardized } \\
\text { Coefficients }\end{array} \\
\text { Beta } \\
\end{array}$} & \multirow[b]{2}{*}{$\mathrm{t}$} & \multirow[b]{2}{*}{ Sig. } \\
\hline & B & Std. Error & & & \\
\hline 1 (Constant) & 3,105 & 0,098 & & 0,000 & 1,000 \\
\hline Pendapatan & $-0,119$ & 0,162 & $-0,119$ & $-0,734$ & 0,467 \\
\hline Harga Barang & 0,300 & 0,132 & 0,300 & 2,275 & 0,028 \\
\hline Selera Individu & $-0,549$ & 0,477 & $-0,549$ & $-1,150$ & 0,256 \\
\hline Status Sosial & 1,206 & 0,398 & 1,206 & 3,027 & 0,004 \\
\hline Kebudayaan & $-0,156$ & 0,271 & $-0,156$ & $-0,577$ & 0,567 \\
\hline
\end{tabular}

a. Dependent Variable: Permintaan

Berdasarkan Tabel 1. di atas dapat diperoleh persamaan regresi linier berganda sebagai berikut:

$$
\begin{aligned}
& \mathbf{Y}=\alpha+\mathrm{X}_{1}+\mathrm{X}_{2}+\mathrm{X}_{3}+\mathrm{X}_{4}+\mathrm{X}_{5}+e \\
& \mathbf{Y}=3,105+(-0,119) \mathbf{X}_{1}+0,300 \mathbf{X}_{2}+(-0,549) \mathbf{X}_{3}+1,206 \mathbf{X}_{4}+(-0,156) \mathbf{X}_{5}+\boldsymbol{e} \\
& \mathbf{Y}=3,105-0,119 \mathbf{X}_{1}+0,300 \mathbf{X}_{2}-0,549 \mathbf{X}_{3}+1,206 \mathbf{X}_{4}-0,156 \mathbf{X}_{5}+e
\end{aligned}
$$

Berdasarkan persamaan regresi linier berganda tersebut menunjukkan arti dan dapat dijelaskan bahwa :

1. Konstanta $(3,105)$

Merupakan nilai konstanta, dengan demikian nilai konstanta ini menunjukan besarnya nilai variabel perilaku konsumen dalam permintaan buah naga di Pasar Mimbaan Situbondo sebesar 3,105, jika variabel lain permintaan sama dengan nol atau konstan.

2. Pendapatan $(-0,119)$

Besarnya koefisien regresi variabel pendapatan $\left(\mathrm{X}_{1}\right)$ yang berarti setiap peningkatan variabel pendapatan konsumen, maka perilaku konsumen terhadap permintaan buah naga menurun 0,119 dengan asumsi variabel lain (harga barang, selera individu, status sosial, dan kebudayaan) konstan.

3. Harga Barang $(0,300)$

Besarnya koefisien regresi variabel harga barang $\left(\mathrm{X}_{2}\right)$ yang berarti setiap peningkatan variabel harga barang, maka perilaku konsumen terhadap permintaan 


\section{Volume 3 , Nomor 1, Juli}

2019 CERMIN : JURNAL PENELITIAN

buah naga meningkat 0,300 dengan asumsi variabel lain (pendapatan, selera individu, status sosial, kebudayaan) konstan.

4. Selera Individu $(-0,549)$

Besarnya koefisien regresi variabel selera individu $\left(\mathrm{X}_{3}\right)$ yang berarti setiap peningkatan variabel selera individu, maka perilaku konsumen terhadap permintaan buah naga menurun 0,549 dengan asumsi variabel lain (pendapatan, harga barang, status sosial, dan kebudayaan) konstan.

5. Status Sosial $(1,206)$

Besarnya koefisien regresi variabel status sosial $\left(\mathrm{X}_{4}\right)$ yang berarti setiap peningkatan variabel status sosial, maka perilaku konsumen terhadap permintaan buah naga meningkat 1,206 dengan asumsi variabel lain (pendapatan, harga barang, selera individu, dan kebudayaan) konstan.

6. Kebudayaan $(-0,156)$

Koefisien variabel regresi kebudayaan $\left(\mathrm{X}_{5}\right)$ yang berarti setiap peningkatan variabel kebudayaan, maka perilaku konsumen terhadap permintaan buah naga menurun 0,156 dengan asumsi variabel lain (pendapatan, harga barang, selera individu, dan status sosial) konstan.

7. e (Std. Error) yaitu nilai residu/kemungkinan kesalahan dari model persamaan regresi yang disebabkan adanya kemungkinan variabel lainnya yang dapat mempengaruhi variabel permintaan (Y) tetapi tidak dimasukkan kedalam model persamaan. Standart error sebesar 0,695 artinya seluruh variabel yang dihitung dalam uji SPSS versi 22 for windows 7 memiliki tingkat variabel pengganggu sebesar 0,098 .

\section{Uji Parsial (Uji t)}

Uji t dilakukan untuk menguji koefisien regresi secara parsial dari variabel independennya. Uji ini dilakukan dengan membandingkan $t_{\text {hitung }}$ dengan $t_{\text {tabel }}$ dengan ketentuan sebagai berikut: 
1. Jika $t_{\text {hitung }}<t_{\text {tabel }}$, atau $-\mathrm{t}_{\text {hitung }}>-\mathrm{t}_{\text {tabel }}$ maka Ho diterima dan Ha ditolak untuk $\alpha=$ $5 \%$,

2. Jika $t_{\text {hitung }}>t_{\text {tabel }}$, atau $-t_{\text {hitung }}<-t_{\text {tabel }}$ maka Ha diterima dan Ho ditolak untuk $\alpha=$ $5 \%$.

Berdasarkan nilai probabilitas sebagai dasar pengambilan keputusan adalah sebagai berikut:

1. Sig. $>\alpha$, untuk $\alpha=5 \%$, maka Ho diterima bila sig. $>0,05$

2. Sig. $<\alpha$, untuk $\alpha=5 \%$, maka Ha diterima bila sig. $<0,05$

Hasil pengujian hipotesis dengan menggunakan uji t dapat dilihat pada Tabel 6. berikut:

\begin{tabular}{|c|c|c|c|c|c|}
\hline \multicolumn{6}{|c|}{$\begin{array}{l}\text { Tabel 2. Hasil Uji t } \\
\text { Coefficients }^{\mathbf{a}}\end{array}$} \\
\hline \multirow[b]{2}{*}{ Model } & \multicolumn{2}{|c|}{$\begin{array}{l}\text { Unstandardized } \\
\text { Coefficients }\end{array}$} & \multirow{2}{*}{$\begin{array}{c}\text { Standardized } \\
\text { Coefficients }\end{array}$} & \multirow[b]{2}{*}{$\mathrm{t}$} & \multirow[b]{2}{*}{ Sig. } \\
\hline & $\mathrm{B}$ & Std. Error & & & \\
\hline $1($ Constant $)$ & 3,105 & 0,098 & & 0,000 & 1,000 \\
\hline Pendapatan & $-0,119$ & 0,162 & $-0,119$ & $-0,734$ & 0,467 \\
\hline Harga Barang & 0,300 & 0,132 & 0,300 & 2,275 & 0,028 \\
\hline Selera Individu & $-0,549$ & 0,477 & $-0,549$ & $-1,150$ & 0,256 \\
\hline Status Sosial & 1,206 & 0,398 & 1,206 & 3,027 & 0,004 \\
\hline Kebudayaan & $-0,156$ & 0,271 & $-0,156$ & $-0,577$ & 0,567 \\
\hline
\end{tabular}

a. Dependent Variable: Permintaan

Mencari t tabel : df $=\mathrm{n}-\mathrm{k}(\alpha / 2)$

$$
\begin{aligned}
& : 50-6=44\left(\frac{0,05}{2}\right)=0,025 \\
& : 44\left(t_{\text {tabel }} 2,015\right)
\end{aligned}
$$

1. Pendapatan $\left(\mathrm{X}_{1}\right)$

Nilai $t_{\text {hitung }}$ untuk variabel Pendapatan sebesar -0,734. Sementara itu nilai pada $\mathrm{t}_{\text {tabel }}$ distribusi 5\% sebesar 2,015, maka $\mathrm{t}_{\text {hitung }}-0,734>\mathrm{t}_{\text {tabel }}-2,015$. Yaitu Ho dterima dan Ha ditolak. Hal ini berarti variabel Pendapatan tidak mempunyai pengaruh signifikan positif. Hal ini juga diperkuat dengan nilai signifikan 0,467>0,05 artinya variabel Pendapatan tidak berpengaruh secara parsial terhadap perilaku konsumen pada permintaan buah naga di Pasar Mimbaan Kecamatan Panji Kabupaten Situbondo. 


\section{Volume 3 , Nomor 1, Juli}

2. Harga Barang $\left(\mathrm{X}_{2}\right)$

Nilai $t_{\text {hitung }}$ untuk variabel Harga Barang sebesar2,275. Sementara itu nilai pada $t_{\text {tabel }}$ distribusi 5\% sebesar 2,015, maka $t_{\text {hitung }} 2,275>t_{\text {tabel }} 2,015$. Yaitu Ho ditolak dan Ha diterima. Hal ini berarti variabel Harga Barang mempunyai pengaruh signifikan positif. Hal ini juga diperkuat dengan nilai signifikan $0,028<0,05$ artinya variabel Harga Barang berpengaruh secara parsial terhadap perilaku konsumen pada permintaan buah naga di Pasar Mimbaan Kecamatan Panji Kabupaten Situbondo.

3. Selera Individu $\left(\mathrm{X}_{3}\right)$

Nilai $t_{\text {hitung }}$ untuk variabel Selera Individu sebesar $-1,150$. Sementara itu nilai pada $t_{\text {tabel }}$ distribusi $5 \%$ sebesar 2,015, maka $t_{\text {hitung }}-1,150>t_{\text {tabel }}-2,015$. Yaitu Ho diterima dan Ha ditolak. Hal ini berarti variabel Selera Individu tidak mempunyai pengaruh signifikan positif. Hal ini juga diperkuat dengan nilai signifikan 0,256> 0,05 artinya variabel Selera Individu tidak berpengaruh secara parsial terhadap perilaku konsumen pada permintaan buah naga di Pasar Mimbaan Kecamatan Panji Kabupaten Situbondo.

4. Status Sosial $\left(\mathrm{X}_{4}\right)$

Nilai $t_{\text {hitung }}$ untuk variabel Status Sosial sebesar 3,027. Sementara itu nilai pada $\mathrm{t}_{\text {tabel }}$ distribusi 5\% sebesar 2,015, maka $\mathrm{t}_{\text {hitung }} 3,027>\mathrm{t}_{\text {tabel }} 2,015$. Yaitu Ho ditolak dan Ha diterima. Hal ini berarti variabel Status Sosial mempunyai pengaruh signifikan positif. Hal ini juga diperkuat dengan nilai signifikan $0,004<0,05$ artinya variabel Status Sosial berpengaruh secara parsial terhadap perilaku konsumen pada permintaan buah naga di Pasar Mimbaan Kecamatan Panji Kabupaten Situbondo.

5. Kebudayaan (X5)

Nilai $t_{\text {hitung }}$ untuk variabel Kebudayaan sebesar -0,577. Sementara itu nilai pada $\mathrm{t}_{\text {tabel }}$ distribusi 5\% sebesar 2,015, maka $\mathrm{t}_{\text {hitung }}-0,577>\mathrm{t}_{\text {tabel }}-2,015$. Yaitu Ho diterima dan Ha ditolak. Hal ini berarti variabel Kebudayaan tidak mempunyai pengaruh 


\section{Volume 3 , Nomor 1, Juli}

2019 CERMIN : JURNAL PENELITIAN

signifikan positif. Hal ini juga diperkuat dengan nilai signifikan $-0,567>0,05$ artinya variabel Kebudayaan tidak berpengaruh secara parsial terhadap perilaku konsumen pada permintaan buah naga di Pasar Mimbaan Kecamatan Panji Kabupaten Situbondo.

\section{Uji Simultan (Uji F)}

Uji simultan atau uji $\mathrm{F}$ merupakan uji secara bersama-sama untuk menguji pengaruh signifikan variabel perilakukonsuemen terhadap permintaan buah naga di Pasar Mimbaan Kecamatan Panji Kabupaten Situbondo.

Tabel 3. Hasil Uji F

\begin{tabular}{|c|c|c|c|c|c|c|}
\hline \multicolumn{7}{|c|}{ ANOVA $^{\mathbf{a}}$} \\
\hline \multicolumn{2}{|c|}{ Model } & $\begin{array}{l}\text { Sum of } \\
\text { Squares }\end{array}$ & Df & Mean Square & $\mathrm{F}$ & Sig. \\
\hline$\overline{1}$ & Regression & 27,732 & 5 & 5,546 & 11,474 & $0,000^{\mathrm{b}}$ \\
\hline & Residual & 21,268 & 44 & 0,483 & & \\
\hline & Total & 49,000 & 49 & & & \\
\hline & ncari $\mathrm{F}$ tabel & $\begin{array}{l}: \mathrm{df}_{1}=\mathrm{K}-1 \\
: \mathrm{df}_{1}=6-1=5 \\
: \mathrm{df}_{2}=\mathrm{n}-\mathrm{K} \\
: 50-6=44\left(\mathrm{~F}_{\mathrm{t}}\right.\end{array}$ & $2,430)$ & & & \\
\hline
\end{tabular}

Berdasarkan Tabel 7. di atas pengujian statistik dengan menggunakan metode uji $\mathrm{F}$, dimana nilai $\mathrm{F}_{\text {hitung }} 11,474>\mathrm{F}_{\text {tabel }} 2,430$ dengan tingkat signifikan yang diperoleh $0,000<0,05$, maka dapat disimpulkan bahwa terdapat pengaruh perilaku konsumen terhadap permintaan buah naga di Pasar Mimbaan Kecamatan Panji Kabupaten Situbondo.

\section{KESIMPULAN DAN SARAN}

\section{Kesimpulan}

Berdasarkan dari hasil penelitian yang telah dilakukan dan telah diuraikan sebelumnya, maka dapat ditarik kesimpulan dari keseluruhan hasil penelitian yaitu:

1. Perilaku konsumen dari beberapa faktor seperti pendapatan, harga barang, selera individu, status sosial dan kebudayaan hanya harga barang dan status sosial yang 


\section{Volume 3 , Nomor 1, Juli}

2019 CERMIN : JURNAL PENELITIAN

mempengaruhi permintaan buah naga di Pasar Mimbaan, sedangkan ketiga faktor seperti pendapatan, selera individu, dan kebudayaan tidak berpengaruh terhadap permintaan buah naga di Pasar Mimbaan.

2. Secara bersama-sama pendapatan, harga barang, selera individu, status sosial dan kebudayaan berpengaruh terhadap permintaanbuah naga di Pasar Mimbaan.

\section{Saran}

Berdasarkan hasil analisa, pembahasan dan kesimpulan di atas beberapa saran yang dapat di ajukan sebagai berikut :

1. Untuk menarik minat konsumen selama proses keputusan pembelian hingga akhirnya dapat mengambil keputusan untuk membeli produk tersebut, pemilik kios harus menetapkan harga yang terjangkau, menetapkan harga yang sesuai kualitas produknya. Sedangkan saat peneliti berada dilapangan harga buah naga melonjak naik, dan hanya kalangan tertentu saja yang bisa membelinya.

2. Perilaku konsumen harus lebih di tingkatkan lagi, salah satu caranya yaitu dengan memberikan penawaran harga yang lebih baik kepada konsumen. Semakin baik harga yang ditawarkan kepada konsumen, maka perilaku konsumen akan semakin baik.

\section{DAFTAR PUSTAKA}

Ghozali, Imam, 2005. Aplikasi Analisis Multivariate Dengan Program SPSS ,Edisi Ketiga, Badan Penerbit Universitas Diponegoro, Semarang.

Kristanto. 2008. Buah Naga Pembudidayaan di Pot dan di Kebun. Penebar Swadaya. Jakarata.

Jaafar R.A., Abdul Rahman A.R. Bin, Mahmod N.Z.C. and Vasudevan R., 2009,Proximate Analysis of Dragon Fruit (Hylocereus polyrhizus), American Journal of Applied Sciences, 6 (7), 1341-1346.

Mowen 1990. Perilaku Konsumen, penerbit Pustaka Ilmu, Jakarta.

Sarnowo, H dan Sunyoto, D. 2013. Pengantar Ilmu Ekonomi Mikro. CAPS : Yogyakarta. 
Sugiyono. (2001). Metode Penilaian. Bandung: Alfabeta.

Sugiyono, (2008). Metode Penelitian Kuantitatif Kualitatif dan R\&D. Bandung Alfabeta.

Sugiyono. 2010. Metode Penelitian Pendidikan Pendekatan Kuantitatif, kualitatif, dan R\&D. Bandung: Alfabeta. 